\title{
$\mathbf{J}|\mathbf{A}| \mathbf{C} \mid \mathbf{S}$ \\ COMMUNICATIONS
}

Published on Web 03/28/2002

\section{Nickel-Catalyzed Cross-Coupling Reaction of Grignard Reagents with Alkyl Halides and Tosylates: Remarkable Effect of 1,3-Butadienes}

\author{
Jun Terao, Hideyuki Watanabe, Aki Ikumi, Hitoshi Kuniyasu, and Nobuaki Kambe* \\ Department of Molecular Chemistry \& Frontier Research Center, Graduate School of Engineering, \\ Osaka University, Yamadaoka 2-1, Suita, Osaka 565-0871. Japan
}

Received February 6, 2002

In 1972, Kumada's group and Corriu's group independently reported cross-coupling reaction of Grignard reagents with aryl and alkenyl halides catalyzed by nickel(II) halides. ${ }^{1}$ The catalytic cycle, which involves oxidative addition, transmetalation, and reductive elimination steps, has become a prototype of a more practical Pdcatalyzed cross-coupling reaction. These reactions proceed smoothly using a variety of organometallic reagents containing $\mathrm{B}, \mathrm{Mg}, \mathrm{Li}$, $\mathrm{Sn}, \mathrm{Al}$, and $\mathrm{Zn}$ as the metal connecting to alkyl, alkenyl, aryl, alkynyl, allyl, and benzyl groups as the organic part. ${ }^{2}$ As for the coupling partner, however, the scope is generally limited to aryl and alkenyl moieties. The use of alkyl halides, triflates, or tosylates usually gives unsatisfactory results due mainly to the slow oxidative addition to transition metal catalysts and the facile $\beta$-elimination from the alkylmetal intermediates. Thus, the alkyl-alkyl crosscoupling reaction catalyzed by transition metal complexes has remained as an interesting and challenging theme to be solved in this field. ${ }^{3-7}$ Recently, we have developed regioselective monoand dialkylation of alkenes or dienes with alkyl halides or tosylates using titanocene ${ }^{8}$ or zirconocene ${ }^{9}$ catalysts. During the course of our study on transition metal catalyzed alkylation reactions, we have found that $\mathrm{Ni}$ catalyzes the cross-coupling reaction of alkyl chlorides, bromides, and tosylates with Grignard reagents in the presence of a 1,3-butadiene as an additive (eq 1).

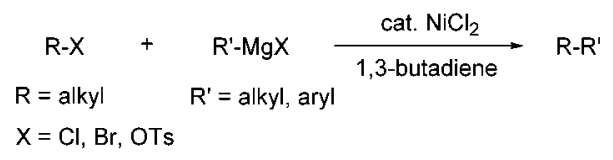

For example, a reaction of $n$-decyl bromide with $n$-butylmagnesium chloride (1.3 equiv) in the presence of isoprene (1.0 equiv) and $\mathrm{NiCl}_{2}\left(0.03\right.$ equiv) at $25{ }^{\circ} \mathrm{C}$ for $3 \mathrm{~h}$ gave tetradecane in $92 \%$ yield along with trace amounts of decane $(<1 \%)$ and decenes $(2 \%)$ (Table 1, entry 1). In the absence of isoprene, tetradecane was obtained in only $2 \%$ yield and significant amounts of decane and decenes were formed (entry 2). The use of $\mathrm{Ni}(\mathrm{acac})_{2}$ and $\mathrm{Ni}(\mathrm{COD})_{2}$ also afforded tetradecane in high yields (entries 3 and 4). When nickel complexes bearing phosphine ligands, such as $\mathrm{NiCl}_{2}\left(\mathrm{PPh}_{3}\right)_{2}$ and $\mathrm{NiCl}_{2}$ (dppp), were used, tetradecane was obtained only in $45 \%$ and $22 \%$ yields, respectively. Under similar conditions, $\mathrm{FeCl}_{3}$ and $\mathrm{CoCl}_{2}$ (dppe) were ineffective, and $\mathrm{PdCl}_{2}$ gave a moderate yield of tetradecane (entry 5). Next, we examined the effect of additives which are essential to promote the present coupling reaction. Unsubstituted 1,3-butadiene shows by far the highest activity for this cross-coupling reaction (entry 6). 2,3-Dimethyl-1,3-butadiene, COD, alkynes, and alkenes are far less effective under the same conditions (entries 7-10).

* Corresponding author. E-mail: kambe@ap.chem.eng.osaka-u.ac.jp.
Table 1. Cross-Coupling Reaction of $n-\mathrm{C}_{10} \mathrm{H}_{21} \mathrm{Br}$ with $n$-BuMgCl

\begin{tabular}{|c|c|c|c|c|c|}
\hline \multirow{2}{*}{ entry } & \multirow{2}{*}{ catalyst } & \multirow{2}{*}{ additive } & \multicolumn{3}{|c|}{ GC yield $(\%)^{a}$} \\
\hline & & & $n-\mathrm{C}_{14} \mathrm{H}_{30}$ & decane & decenes $^{b}$ \\
\hline 1 & $\mathrm{NiCl}_{2}$ & & 92 & $<1$ & 2 \\
\hline 2 & $\mathrm{NiCl}_{2}$ & none & 2 & 49 & 27 \\
\hline 3 & $\mathrm{Ni}(\text { acac })_{2}$ & & 90 & $<1$ & 2 \\
\hline 4 & $\mathrm{Ni}(\mathrm{COD})_{2}$ & & 92 & $<1$ & 3 \\
\hline 5 & $\mathrm{PdCl}_{2}$ & & 38 & 1 & 3 \\
\hline 6 & $\mathrm{NiCl}_{2}$ & & 99 & $<1$ & 0 \\
\hline 7 & $\mathrm{NiCl}_{2}$ & & 5 & 14 & 9 \\
\hline 8 & $\mathrm{NiCl}_{2}$ & $\operatorname{COD}^{\mathrm{C}}$ & 10 & 18 & 38 \\
\hline 9 & $\mathrm{NiCl}_{2}$ & $\mathrm{Ph}=\mathrm{Et}$ & 3 & 7 & 23 \\
\hline 10 & $\mathrm{NiCl}_{2}$ & 3-CF ${ }_{3}$-styrene & 15 & 25 & 14 \\
\hline
\end{tabular}

${ }^{a}$ Conditions: $n-\mathrm{C}_{10} \mathrm{H}_{21} \mathrm{Br}(2 \mathrm{mmol})$, catalyst $(3 \mathrm{~mol} \%), n-\mathrm{BuMgCl}(1.3$ equiv, $0.9 \mathrm{M}$ ), additive (1 equiv, $0.7 \mathrm{M}) ; 25^{\circ} \mathrm{C} ; 3 \mathrm{~h} .{ }^{b} \mathrm{~A}$ mixture of 1 -decene and 2-decenes. ${ }^{c}$ 1,5-Cyclooctadiene.

Optimization of the reaction conditions using 1,3-butadiene revealed that use of only $1 \mathrm{~mol} \%$ of $\mathrm{NiCl}_{2}$ and $10 \mathrm{~mol} \%$ of $1,3-$ butadiene ( $0.07 \mathrm{M}$ in THF, 10 equiv to $\mathrm{Ni}$ catalyst) based on the halides at $0{ }^{\circ} \mathrm{C}$ afforded coupling products quantitatively in the reaction of primary bromides with primary alkyl Grignard reagents (Table 2, entries 1 and 2). Interestingly, the bromo substituent on the aryl ring remained intact in this reaction system (entry 2). This cross-coupling reaction also proceeds efficiently by using alkyl tosylates (entries 3-5). It should be noted that alkyl chlorides can also undergo this cross-coupling reaction, giving rise to the desired products in good yields (entry 8). This is the first example of crosscoupling of inactivated alkyl chlorides. ${ }^{7}$ Aryl and secondary alkyl Grignard reagents also afforded the corresponding products in moderate to good yields (entries 5-7), but no reaction took place with $\mathrm{CH}_{2}=\mathrm{CHMgBr}$ and $\mathrm{PhC} \equiv \mathrm{CMgCl}$ under similar conditions and most of the alkyl bromides were recovered.

To elucidate the reaction pathway, we first performed a reaction of $\mathrm{NiBr}_{2}$ with 2 equiv of $n$-octylmagnesium chloride in the presence of isoprene $\left(0.7 \mathrm{M}\right.$ in THF) at $25{ }^{\circ} \mathrm{C}$ for $15 \mathrm{~min}$. This reaction gave octane and 1-octene in $43 \%$ and $45 \%$ yields, respectively; however, homocoupling product, $n$-hexadecane, was not formed. Assuming that $\mathrm{NiBr}_{2}$ reacts with $n$-octylmagnesium chloride to form $n$-Oct-Ni-Br, this result implies that the present coupling reaction does not involve a process of oxidative addition of alkyl halides to $\mathrm{Ni}(0)$ since this process also affords $n$-Oct-Ni-Br. It was also confirmed that $n$-decyl bromide does not undergo oxidative addition toward $\mathrm{Ni}(\mathrm{COD})_{2}$ in THF containing 1,3 -butadiene $(0.7 \mathrm{M})$ at 0 ${ }^{\circ} \mathrm{C}$ resulting in the recovery of $n$-decyl bromide.

To examine the intermediary of alkyl radicals, we then carried out the coupling reaction of (bromomethyl)cyclopropane with $n$-Oct- 
Table 2. Ni-Catalyzed Cross-Coupling Reaction of Alkyl Halides and a Tosylate with Grignard Reagents

\begin{tabular}{|c|c|c|c|c|c|c|c|c|}
\hline entry & $R-X$ & $\begin{array}{c}\mathrm{R}^{\prime}-\mathrm{Mg} \mathrm{X}^{\prime} \\
\text { (equiv to } \mathrm{R}-\mathrm{X} \text { ) }\end{array}$ & $\begin{array}{c}\mathrm{NiCl}_{2} \\
(\mathrm{~mol} \%)\end{array}$ & $\begin{array}{c}\text { 1,3-butadiene } \\
(\mathrm{mol} \%)^{a}\end{array}$ & $\begin{array}{l}\text { temp. } \\
\left({ }^{\circ} \mathrm{C}\right)\end{array}$ & $\begin{array}{l}\text { time } \\
\text { (h) }\end{array}$ & product & yield $(\%)^{b}$ \\
\hline 1 & ${ }^{\mathrm{n}} \mathrm{C}_{10} \mathrm{H}_{21}-\mathrm{Br}$ & ${ }^{\mathrm{n}} \mathrm{Bu}-\mathrm{MgCl}(1.3)$ & 1 & $10(0.07 \mathrm{M})$ & 0 & 0.5 & ${ }^{\mathrm{n}} \mathrm{C}_{14} \mathrm{H}_{30}$ & 100 \\
\hline 2 & & ${ }^{\mathrm{n}} \mathrm{Bu}-\mathrm{MgCl}(1.3)$ & 1 & $10(0.07 \mathrm{M})$ & 0 & 0.5 & & 100 \\
\hline 3 & $\mathrm{Ph} \sim$ OTs & $\mathrm{Et}-\mathrm{MgBr}(1.3)$ & 3 & $30(0.23 \mathrm{M})$ & 0 & 3 & & 87 \\
\hline 4 & ${ }^{\mathrm{n}} \mathrm{Bu}-\mathrm{OTs}$ & ${ }^{\mathrm{n}} \mathrm{Bu}-\mathrm{MgCl}(1.3)$ & 3 & $100(0.69 \mathrm{M})$ & 0 & 3 & ${ }^{n} \mathrm{C}_{8} \mathrm{H}_{18}$ & 100 \\
\hline 5 & Et-OTs & $\mathrm{Ph}-\mathrm{MgBr}(1.3)$ & 3 & $100(0.77 \mathrm{M})$ & 0 & 6 & Et-Ph & 56 \\
\hline 6 & ${ }^{\mathrm{n}} \mathrm{Oct}-\mathrm{Br}$ & $\mathrm{Ph}-\mathrm{MgBr}(1.3)$ & 3 & $30(0.23 \mathrm{M})$ & 25 & 3 & ${ }^{\mathrm{n}}$ Oct-Ph & 90 \\
\hline 7 & ${ }^{\mathrm{n}} \mathrm{Oct}-\mathrm{Br}$ & $\succ \mathrm{MgCl}(3.0)$ & 3 & $30(0.07 \mathrm{M})$ & 0 & 0.5 & ${ }^{\mathrm{n}} \mathrm{Oct}-$ & 72 \\
\hline 8 & ${ }^{\mathrm{n} O c t-\mathrm{Cl}}$ & ${ }^{\mathrm{n}} \mathrm{Bu}-\mathrm{MgCl}(2.0)$ & 3 & $50(0.23 \mathrm{M})$ & 25 & 20 & ${ }^{\mathrm{n}} \mathrm{C}_{12} \mathrm{H}_{26}$ & 96 \\
\hline
\end{tabular}

${ }^{a}$ Based on $\mathrm{R}-\mathrm{X}$ (concentration is in parentheses). ${ }^{b}$ Determined by GC.

Scheme 1. A Plausible Reaction Pathway

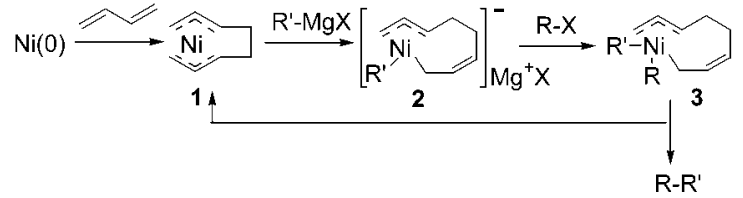

$\mathrm{MgCl}$ under identical conditions of entry 1 in Table 2. Nonylcyclopropane was obtained as the sole coupling product in $87 \%$ yield (eq 2) without formation of 1-dodecene, which may arise from ringopening of the cyclopropylmethyl radical. ${ }^{10}$ This result would rule out a radical mechanism. ${ }^{11}$

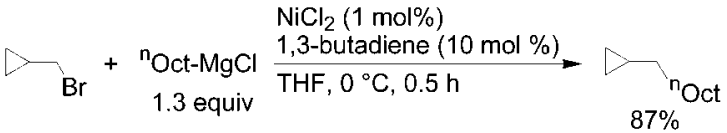

Considering the foregoing results, we propose a plausible reaction pathway as depicted in Scheme 1. The added $\mathrm{NiCl}_{2}$ is reduced to $\mathrm{Ni}(0)$ by the reaction with ${ }^{\mathrm{n}} \mathrm{BuMgCl}$. It is known that $\mathrm{Ni}(0)$ reacts with 2 equiv of 1,3-butadiene to afford bis- $\pi$-allyl nickel complex $\mathbf{1},{ }^{12}$ which reacts with Grignard reagents to form $\eta^{1}, \eta^{3}$-octadienediylnickelate complex $2 .{ }^{13}$ Coupling products might be formed by oxidative addition of alkyl halides to $\mathbf{2}$ yielding dialkylnickel complex 3, followed by reductive elimination. Butadienes play an important role in converting $\mathrm{Ni}(0)$ to $\mathrm{Ni}(\mathrm{II})$ (1), which is less reactive toward $\mathrm{R}-\mathrm{X}$ but readily reacts with $\mathrm{R}^{\prime}-\mathrm{MgX}$ to form 2 as a key intermediate. This complexation might enhance nucleophilicity of Ni toward $\mathrm{R}-\mathrm{X}$.

In conclusion, a novel method for the cross-coupling reaction of Grignard reagents with alkyl chlorides, bromides, and tosylates has been developed with the aid of $\mathrm{Ni}$ catalysts. This reaction proceeds efficiently by the use of primary and secondary alkyl- or arylmagnesium halides under mild conditions. The use of 1,3butadiene as an additive instead of phosphine ligands is the key to attaining high yields of the cross-coupling products.

Acknowledgment. This research was supported financially in part by a grant from the Ministry of Education, Culture, Sports, Science and Technology of Japan. We thank the Instrumental Analysis Center, Faculty of Engineering, Osaka University, for assistance in obtaining HRMS and elemental analysis.
Supporting Information Available: Experimental procedures and compound characterization data (PDF). This material is available free of charge via the Internet at http://pubs.acs.org.

\section{References}

(1) (a) Tamao, K.; Sumitani, K.; Kumada, M. J. Am. Chem. Soc. 1972, 94 , 4374-4376. (b) Corriu, R. J. P.; Masse, J. P. Chem. Commun. 1972, 144

(2) Metal-catalyzed Cross-coupling Reactions; Diederich, F., Stang, P. J., Eds.; Wiley-VCH: New York, 1998.

(3) Alkyl iodides having no $\beta$-hydrogen can be employed in conventional cross-coupling reaction with Grignard reagents. For example, see: Yuan, K.; Scott, W. J. Tetrahedron Lett. 1991, 32, 189-192.

(4) The Suzuki-Miyaura reaction can be applied to alkyl-alkyl coupling of alkyl iodides with alkylboranes, where alkyl radicals are proposed to be involved as key intermediates; (a) Ishiyama, T.; Abe, S.; Miyaura, N.; Suzuki, A. Chem. Lett. 1992, 691-694. Recently, Fu succeeded in applying this reaction to alkyl bromides by using $\mathrm{PCy}_{3}$ as the ligand: (b) Netherton, M. R.; Dai. C.; Neuschütz, K.; Fu, G. C. J. Am. Chem. Soc. 2001, 123, 10099-10100

(5) For a Ni-catalyzed cross-coupling of primary alkyl iodides with organozinc reagents, see: (a) Park, K.; Yuan, K.; Scott, W. J. J. Org. Chem. 1993 58, 4866-4870. (b) Giovannini, R.; Stüdemann, T.; Devasagayaraj, A.; Dussin, G.; Knochel, P. J. Org. Chem. 1999, 64, 3544-3553 and references sited therein.

(6) For other transition metal-catalyzed cross-coupling reactions using alkyl halides, see recent reviews: (a) Luh, T.-Y.; Leung, M.; Wong, K.-T. Chem Rev. 2000, 100, 3187-3204. (b) Cárdenas, D. J. Angew. Chem., Int. Ed. 1999, 38, 3018-3020.

(7) For stoichiometric reactions of cuprates with alkyl chlorides, see: (a) Whitesides, G. M.; Fischer, W. F.; San Filippo, J.; Bashe, R. W.; House, H. O. J. Am. Chem. Soc. 1969, 91, 4871-4882. (b) Lipshutz, B. H.; Parker, D.: Kozlowski, J. A.; Miller, R. D. J. Org. Chem. 1983, 48, 3334-3336. (c) For recent Ni-catalyzed cross-coupling reactions using aryl chlorides, see: Li, G. Y.; Marshall, W. J. Organometallics, 2002, 21, 590-591 and references sited therein.

(8) Terao, J.; Saito, K.; Nii, S.; Kambe, N.; Sonoda, N. J. Am. Chem. Soc. 1998, 120, 11822-11823.

(9) Terao, J.; Watanabe, T.; Saito, K.; Kambe, N.; Sonoda, N. Tetrahedron Lett. 1998, 39, 9201-9204.

(10) Ti-catalyzed alkylation of olefins with alkyl halides proceeds via radical intermediates, see ref 8 and references therein.

(11) It is suggested that oxidative addition of alkyl halides to $\mathrm{Ni}(0)$ may proceed via a radical pathway, see: Weston, C. W.; Verstuyft, A. W.; Nelson, J. H.; Jonassen, H. B. Inorg. Chem. 1977, 16, 1313-1317.

(12) This can be an $\eta^{1}, \eta^{3}$-octadienediylnickel complex or a mixture of these species, see: Benn, R.; Büssemeier, B.; Holle, S.; Jolly, P. W.; Mynott, R.; Tkatchenko, I.; Wilke, G. J. Organomet. Chem. 1985, 279, 63-86.

(13) For magnesium nickelate complexes, see: (a) Kaschube, W.; Pörschke, K. R.; Angermund, K.; Krüger, C.; Wilke, G. Chem. Ber. 1988, 121 , 1921-1929. A similar lithium $\eta^{1}, \eta^{3}$-octadienediyl(phenyl)nickelate complex has been reported, see: (b) Holle, S.; Jolly, P. W.; Mynott, R.; Salz R. Z. Naturforsch., B: Anorg. Chem. Org. Chem. 1982, 37, 675-676. JA025828V 